\title{
THE NUMBER OF PICKERS AND STOCK-KEEPING UNIT ARRANGEMENT ON A UNI- DIRECTIONAL PICKING LINE
}

\author{
R. Hagspihl ${ }^{1} \&$ S.E. Visagie ${ }^{2 *}$ \\ Department of Logistics \\ Stellenbosch University, South Africa \\ ${ }^{2}$ svisagie@sun.ac.za
}

\begin{abstract}
The order picking process is often the single largest expense in a distribution centre (DC). The DC considered in this paper uses a picking line configuration to perform order picking. The number of pickers in a picking line, and the initial arrangement of stock-keeping units (SKUs), are two important factors that affect the total completion time of the picking lines. In this paper, the picking line configuration is simulated with an agent-based approach to describe the behaviour of an individual picker. The simulation is then used to analyse the effect of the number of pickers and the SKU arrangement. Verification and validation of this model shows that the model represents the real-world picking line to a satisfactory degree. Marginal analysis (MA) was chosen to determine a 'good' number of pickers by means of the simulation model. A look-up table is presented to provide decision support for the choice of a 'good' number of pickers to improve completion times of the picking line, for the properties of a specific picking line. The initial SKU arrangement on a picking line is shown to be a factor that can affect the level of picker congestion and the total completion time. The greedy ranking and partitioning (GRP) and organ pipe arrangement (OPA) techniques from the literature, as well as the historical SKU arrangements used by the retailer under consideration, were compared with the proposed classroom discipline heuristic $(C D H)$ for SKU arrangement. It was found that the CDH provides an more even spread of SKUs that are picked most frequently, thus decreasing congestion and total completion time.
\end{abstract}

\section{OPSOMMING}

Die opmaak van bestellings is meestal die enkele grootste uitgawe in ' $\mathrm{n}$ distribusiesentrum (DS). Die DS wat hier beskou word gebruik 'n opstelling in die vorm van 'n uitsoeklyn om bestellings vir die winkels op te maak. Die aantal werkers en die rangskikking van voorraadeenhede in die uitsoeklyn is twee belangrike faktore wat die totale afhandelingstyd beïnvloed. In hierdie artikel word 'n uitsoeklyn met behulp van agentgebaseerde simulasie gemodelleer om die gedrag van 'n individuele werker te simuleer. Hierdie simulasie word dan gebruik om die effek van die aantal werkers en die voorraad se rangskikking te analiseer. Verifiëring en validering van die model wys dat die model wel die werklike uitsoeklyn bevredigend naboots. Grensontleding word gebruik om 'n goeie aantal werkers vir 'n uitsoeklyn te bepaal. 'n Tabel word verskaf om die regte aantal werkers vir 'n nuwe Iyn na te slaan. Die aanvanklike rangskikking van die voorraadeenhede in die uitsoeklyn beïnlvoed die kongestie en die totale afhandelingstyd. Die gulsige rangskikkingen-verdeling en die orrelpyp rankskikkings uit die literatuur, sowel as die historiese rankskikking deur die kleinhandelaar, word vergelyk met die voorgestelde klaskamerdissipline-heuristiek (KDH) vir voorraad rangskikking. Die bevinding word gemaak dat die $\mathrm{KDH}$ 'n beter verspreiding van voorraadeenhede oor die lyn bewerkstellig, wat lei tot die verlaging van die totale kongestie en afhandelingstyd van 'n uitsoeklyn.

Corresponding author 


\section{$1 \quad$ INTRODUCTION}

Distribution centres (DCs) play a vital role in the supply chain of most retail companies, linking the manufacturers, suppliers, and consumers. The costs associated with DCs account for a significant part of the total supply chain cost of most companies, and therefore it is important to optimise the DC operations to minimise these costs. Order picking is usually the most labour-intensive and cost-inducing process in a DC: it can account for as much as 55 per cent of the total DC operating cost [4]. So there has been much research into different order picking policies and systems to optimise this process. DCs have different requirements due to the facility setup, product range, and order properties. These different requirements have led to a number of variations in order picking policies and systems being implemented in different DCs. These policies and systems determine the manner and sequence in which stock-keeping units (SKUs) are picked to complete an order. This paper considers the picking operations of a DC owned by PEP Stores Ltd, the biggest single brand retailer in South Africa [13].

The three main order picking systems implemented around the world are the 'picker-toparts system', the 'parts-to-picker' system, and the 'put system' [4]. There are also automated picking systems, yet these are less frequently used, being reserved for more specialised types of products. The majority of order picking systems employ people. PEP uses the most commonly implemented system, the 'picker-to-parts system'. In this system the picker(s) move along aisles to bays where SKUs are situated. PEP, however, does not pick directly from the storage locations, but takes a set of SKUs to a designated picking area (called a picking line) to perform the order picking on that set of SKUs.

The picking lines in PEP's DC are designed with 56 locations situated around a conveyor belt, as shown in Figure 1. The picking line is built prior to order picking, according to a set of distributions received from head office. A distribution contains a group of SKUs and the quantities that each branch requires of each SKU in that group. A set of distributions is clustered together; all the SKUs in that cluster are put together on a picking line, and are then picked as a wave. If the SKUs for all the branches are picked, the leftover stock is removed from the line and a new set of distributions is assigned to a line; this results in picking waves. During a wave, each location is allocated a maximum of one type of SKU. Picking line managers make the decisions about the placement of SKUs on the line. They usually attempt to place the SKUs in such a way that the SKUs that are picked most often (i.e. go to the most branches) during the picking process are spread out over the different lines. This spreading of the most-picked SKUs is done to avoid unbalanced workload amongst pickers. Moreover, pickers hinder each other if the most-picked SKUs are placed close together on a picking line; this leads to picker congestion. Congestion refers to any picker standing still or moving slower because they cannot easily pass another picker who walks at a slower speed or is stationary in front of them because they are busy picking themselves. Congestion may potentially increase the total completion time of a picking line. The first objective of this paper is thus to investigate the effect of the SKU arrangement on picker congestion, and to find SKU arrangements that may lead to lesS congestion. Since it has been shown that the SKU arrangement does not significantly affect the number of cycles walked by pickers to pick all the orders, this study uses the SKU arrangement to decrease picker congestion and ultimately the total picking time. 


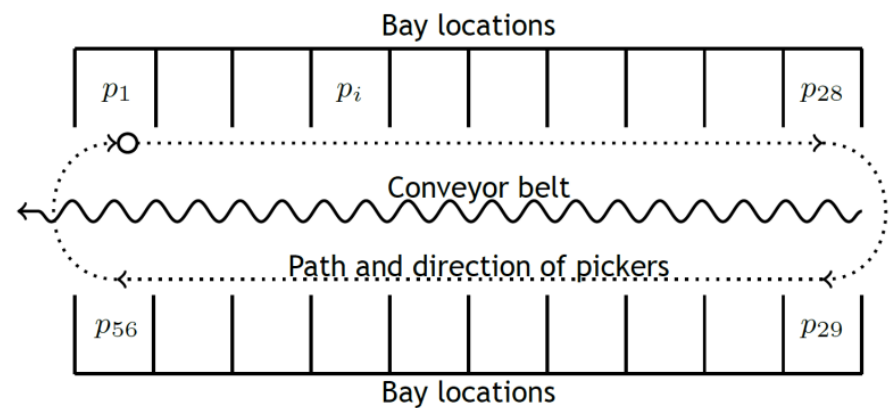

Figure 1: A schematic representation of a 56-bay picking line at PEP's DC.

The pickers assigned to a picking line walk around the conveyor belt, picking different SKUs from locations to complete specific orders. The pickers are each equipped with an audio headpiece that uses a voice recognition system (VRS). This software leads them to pick the correct quantity of a specific SKU for a particular order they have been assigned. Pickers only pick one order at a time, and do this in a clockwise direction at all times. Once an order (for a branch) is completed, the picker places that order on to the conveyor belt to be transported to a station for quality control checks, and then to dispatch for shipping to its branch. A picker who has completed an order receives a new order to pick. This process is repeated until all the orders have been completed. The picking line managers decide on the number of pickers assigned to a specific picking line during a wave of picking. In practice, this number is determined based on the picking line manager's common sense and experience. Approximately eight pickers (depending on the size of a line) are normally assigned to a picking line.

A carousel is a circular setup of shelving that contains products and brings them to a picker, instead of a picker walking to the product. The carousel can rotate (usually) in both directions to present the products to a picker [10]. The picking line setup described above may be viewed as a type of uni-directional carousel system, where the carousel is stationary, but the pickers rotate. There are, however, two major differences between the picking lines considered here and carousels described in the literature: (a) the picking lines considered here result in a uni-directional carousel as opposed to the bi-directional case described most often in the literature; and (b) the carousels in the literature are optimised for an expected (stochastic) set of orders, while these picking lines are optimised for a known (deterministic) set of orders. The existing literature on carousels is thus not applicable to the picking line configuration considered in this paper.

The main aim of this paper is accurately to simulate the picking process at PEP's Durban $D C$, and to provide, by means of the simulation, an analysis on the impact of the placement of SKUs and the number of pickers on the congestion in a picking line. Furthermore, the analysis should provide a 'good' number of pickers and SKU arrangement to improve the total completion times of the picking lines.

The remainder of the paper is structured as follows: in Section 2 the simulation model, the input data, and the validation and verification of the simulation model are discussed. The results of the simulation model are presented in Section 3, in terms of the SKU arrangement and the number of pickers in a picking line. The paper is concluded in Section 4.

\section{THE MODELLING APPROACH}

Simulations are used widely to optimise DC operations, and have been proven to provide practical and implementable results [7]. The interactions between pickers on the picking lines in the DC considered here are too complex to be modelled analytically, and thus a simulation model was implemented. Agent-based modelling and simulation (ABMS) is a relatively new tool that is very useful in modelling the dynamic nature of a complex system 
with a collection of autonomous decision-making 'agents' [11]. These agents are able to dynamically assess their current situation and act accordingly. These actions are governed by behavioural traits. ABMS allows agents to make decisions and act independently of each other, yet also allows agents to interact and adapt to certain environmental pressures.

ABMS can be computationally expensive because it does not look at the aggregate level of a system, but instead deals with the system's constituent entities [2]. In dealing with these, ABMS provides a method in which many systems can be modelled in their most natural states. For example, it is more natural to model a traffic intersection through the behaviour of individual cars than to describe the congestion through a range of complex equations, because the congestion is a direct result of the behavioural traits of individual cars that want to use the intersection at the same time.

One of the benefits of ABMS is the flexible nature of the model. It provides a framework in which the complexity of the agents' behavioural characteristics and the rules of inter-agent relationships can be changed and tweaked in a dynamic manner [2]. This fine-tuning of a model typically occurs in a verification and validation process to simulate a real-life system more accurately.

\subsection{Simulation model}

Macal and North [11] suggest that any ABMS model has three elements. It is crucial that a developer identifies these elements correctly in the process of building a model. The first element is a set of agents with their characteristics and behavioural traits. The second element is a set of agent relationships that define the manner in which agents interact with each other and the environment. The third element is the environment within which the agents exercise their behaviour and inter-agent relationships.

In the modelling process presented here, the pickers are seen as the agents. They are assigned a set of characteristics and behavioural traits that define their actions and their interactions with other agents. They are situated in an environment (the picking line) that determines the boundaries within which they operate.

The Oxford Advanced Learner's Dictionary [4] defines 'maturity' as "the state of being fully grown or developed". When this concept is applied to a project, it could imply a situation where an organisation has standards and procedures in place that would assist it in reaching its objectives. An organisation is mature, therefore, when it is in a position to deal perfectly with its projects [5].

\subsubsection{Agent characteristics}

The three maj or activities that any picker performs are walking, picking, and packing. The 'walking' activity involves walking from one specific location to another, where the next SKU (in a clockwise direction) required by the current order is situated. 'Picking' is the activity of selecting the correct number of that specific SKU from the location to be packed in a carton. The 'packing' activity involves packing the picked SKUs for an order into the carton in an orderly manner (pickers are rewarded for packing tightly), placing full boxes or completed orders on to the conveyor belt, and preparing new boxes for the next order.

Walking occurs at different velocities that depend on the specific picker and the picker's direct environment. Similarly, the picking and packing occurs at picker-specific times. The picking and packing times for any specific picker vary from pick to pick and pack to pack. Both of these times are expected to be exponentially distributed. The walking velocity, the picking and packing times, and the current location in the picking line are defined as the agent's characteristics. At any point in time, an order to be completed and a next location to be visited are assigned to a picker; thus these are also viewed as characteristics.

The visual analysis performed in the DC revealed that the current velocity of a picker is largely dependent on the current velocity and activities of the pickers who are working close to one another. From time studies of video footage taken in the DC, it was concluded 
that a picker can be in one of four velocity states: default velocity, following velocity, passing velocity, and congested velocity.

The 'default' velocity state refers to when a chosen picker is not within a critical distance to any other picker, and thus can walk at their default velocity. This default velocity is assigned to the picker during the initialisation process of the simulation. If the chosen picker is within a critical distance of another picker, the behaviour of the picker in front of them is observed and a decision is made accordingly; the picker in front could be walking at their default velocity, picking, packing, or in a congested state.

If the picker in front of the current picker is walking, then the current picker will assume a 'following' velocity state, taking on the default velocity of the picker in front of them, and following that picker until there is a change in the status quo. If the picker in front is either picking or packing, and thus stationary, there are two possibilities to consider: the picker in front could be either picking or packing where the current picker intends to pick their next SKU. If the picker in front is not picking or packing where the current picker intends to pick next, the chosen picker assumes the 'passing' velocity state and passes the picker in front at a reduced velocity: this is set as a percentage of the chosen picker's default velocity. If the picker in front is indeed picking where the current picker intends to pick next, then the current picker assumes the 'congested' velocity state, waiting for the picker in front to move on: this occurs as pickers cannot pick from the same location simultaneously. Finally, if the picker in front is in a 'congested' velocity state, the chosen picker also assumes the 'congested' velocity state because there is no possibility of passing. This decision process is represented by the flow diagram in Figure 2.

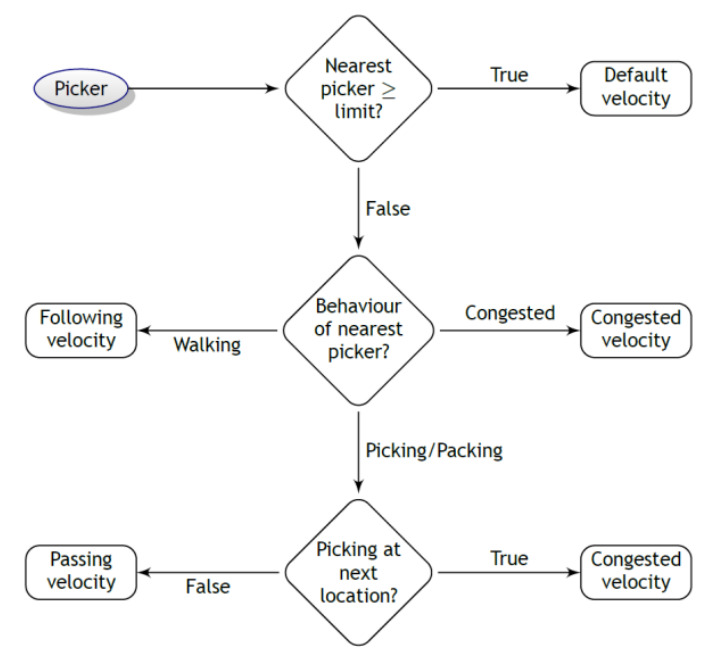

Figure 2: A flow diagram defining the velocity state of a picker

\subsubsection{Environment}

The environment emulates the layout of the picking line in PEP's Durban DC. The environment is designed and scaled precisely, and dictates the allowable whereabouts of the picker, along with the uni-directional nature of the picking line. From the scaled distances in the environment, the distance between pickers is evaluated, and behavioural decisions are made accordingly.

\subsubsection{Implementation}

The simulation model, which was developed by XJ Technologies [17] and is based on the $\mathrm{J}$ ava [16] computer programming language, was built and implemented in Anylogic version 6.5.1. The distance between agents is monitored at regular time intervals, and thus behavioural decisions are also taken at regular time intervals, governed by a set of nested 'if' statements. The inputs for the simulation include a list of locations and the respective 
SKUs, a list of store orders with all the SKUs required by each, and the number of pickers to pick these orders. In the verification and validation process of the model, the distributions of the specific picker velocities, the pick and pack times, and the system entry times are required as input in order to compare the simulation output with the real-life situation.

\subsection{The data capturing process}

The analysis of video recordings was used to determine the proportion of time spent picking, packing, and walking by each picker. Using these proportions, it is possible from the picker-specific time stamp data supplied by PEP to calculate the average picking and packing times, and walking velocity for a certain picker, not taking congestion into consideration. In the calculation of the average picking and packing times and average walking velocity for a picker, cycles without excessive time delays were considered. An excessive time delay would be a gap of more than ten minute between two pick time completions, which could be the result of a toilet or lunch break, or a manager calling a picker out of a line. Over these cycles, it can be calculated how many bays were passed, how many picks were made, how many times the picker packed, and the total time spent picking these cycles.

Historical time stamp data and video footage of order picking at the DC was used to analyse the system and to perform the verification and validation. The Kolmogorov-Smirnoff 'goodness of fit' test was used to determine whether the picking and packing times measured from the video footage are in fact exponentially distributed. The hypothesis that the picking and packing times are exponentially distributed is not rejected at a significance level of $\alpha=0.05$.

\subsection{Verification and validation}

A significant and critical process in any simulation is the verification and validation of the model [14]. Without thorough verification and validation, there can be no confidence in the simulation and the respective results. Verification is the process of testing whether the real-world system has been transformed into an accurate computer model, and validation is the substantiation that the model has sufficient accuracy for the purpose at hand [15]. According to Robinson [14], there are four main processes involved with the verification and validation of a simulation model: conceptual model verification and validation, data verification and validation, white-box verification and validation, and black-box verification and validation.

Conceptual model verification and validation is concerned with whether or not the model contains all the relevant detail to meet the proposed objectives: is the detail involved in the ABMS sufficient to analyse the effect of the number of pickers and the SKU arrangement on the picking line's congestion? It was observed (in real life and in the simulation model) that the SKU arrangement and the number of pickers are both large influencers of the amount of congestion present in picking lines.

During data verification and validation, the model builder determines whether or not the data required to run the model is accurate and sufficient. The data input into the Anylogic program was obtained from the historical data automatically captured by the warehouse management system and/or the historical data from the video footage. These two sets of data were then compared by inspection and Kolmogorov-Smirnov 'goodness of fit' tests (at a significance level of $\alpha=0.05$ ) for properties such as the picker's walking times, and was found to yield approximately the same distributions for all input data; thus it was concluded that the input data is accurate.

The white-box verification and validation process determines whether or not the constituent entities accurately model their real-world counterparts. In performing the white-box verification and validation, a few areas were considered:

- $\quad$ Does a single picker walk at the correct velocity and pick and pack at the correct times? 
- Does a single picker pick all the orders in the correct sequence?

- Do pickers stay within the boundaries of the environment and walk in the correct direction?

- Do pickers exhibit the correct inter-agent behaviour?

The agent behaviour was also observed in the Anylogic run time visual and shown to adhere to all specified rules. It was found that the entities accurately emulated the behaviour displayed by pickers in real life.

Black-box verification and validation determines whether or not the simulation models the real world sufficiently at an aggregate level. This is the most difficult but most important part of the verification and validation process. Once the correctness of the model has been ascertained and observed, a comparison of the model's output data with the historical data must be performed. In the black-box verification and validation, a historical dataset was considered. This includes the bay numbers, the corresponding SKU numbers, and the list of orders. It also includes the list of pickers and the relevant picker-specific data.

The times used to calculate the picking and packing times and walking velocity include congestion, and thus need to be adjusted to take congestion into account. Average congestion was calculated over several runs and then removed to calculate the pickerspecific picking and packing times and walking velocities. What must be taken into consideration in this verification and validation are the outliers. Outlying times arise for various reasons such as bathroom or lunch breaks. A few elements that were significantly different (by two standard deviations) were removed from the dataset as outliers for verification and validation purposes, as these were not considered to be normal picker behaviour.

Using the picker-specific data and taking congestion and outliers into account, the blackbox verification and validation could be performed. There are two measures of the model's accuracy: the first is a specific picker's total completion time over all the respective orders, and the second is the picker's specific completion times for every individual store order picked.

Simulation runs were performed, and the differences between the actual times and the simulated times for order completion and total completion were recorded and calculated. The Kolmogorov-Smirnoff 'goodness of fit' test may be used to test if the differences are significantly different from a normal distribution with mean zero. The hypothesis that the differences are normally distributed, with a mean of zero, was not rejected at a significance level of $\alpha=0.05$; thus it is concluded from the verification and validation that the simulation does indeed have an acceptable level of accuracy that is sufficient for modelling the real-world picking lines considered here.

\subsection{Number of replications}

The number of simulation replications influences the accuracy of the solutions acquired. Burghout [3] suggests the following formula to determine the required number of replications. This equation is derived from a statistical (1- $\alpha)$ per cent confidence level ttest on the simulated mean. The number of simulation runs needed is:

$N(m)=\left(\frac{S(m) t_{m-1,1-\alpha / 2}}{\bar{X}(m) \epsilon}\right)^{2}$

where $N(m)$ is the number of replications, $\bar{X}(m)$ is the estimate of the real completion time using $m$ simulation runs, $S(m)$ is the standard deviation over $m$ simulations, $\varepsilon$ is the percentage error of the simulated mean, and $t_{m-1,1-\alpha / 2}$ is the two-tailed t-distribution critical value for $m-1$ degrees of freedom at an $\alpha$ significance level.

It is not possible to use the historical total completion times when using formula (2) in this study. This is because the pickers who start a line often do not complete that line: pickers 
are added and removed from lines by line managers as they see fit. Therefore the completion times for specific pickers were used for this calculation. The standard deviation of the total completion times over twenty simulation replications is 377 seconds, which is 1.5 per cent of the simulated mean completion time of 21,241 seconds. The actual historical completion time was 21,330 seconds. If we accept an error of a minute per hour, it renders $\varepsilon=0.016$. The t-distribution critical value is 2.093 . Substituting this into formula (2) calculates the required number of replications as approximately 4.9. Although roughly five simulation replications are adequate in providing a solution that is sufficiently close to the actual completion time of a picker, ten replications were used throughout this study. This amounts to a maximum error of approximately 42 seconds per hour or 1.17 per cent.

\section{RESULTS}

Sixteen real-life datasets (of picking lines) are considered: they are the same set of picking lines that were used by Matthews and Visagie [12]. The picking lines were divided into eight large lines, four medium lines, and four small lines according to the number of orders associated with the picking lines. These real-life datasets were selected to compare the simulation results with the historical values. Due to a steep increase in run times, only up to sixteen pickers are considered for a 'good' number of pickers; this is because management has confirmed that it is unrealistic for PEP to assign more than double the number of pickers currently being used.

\subsection{SKU arrangement}

The picking lines considered in this paper can be viewed as a type of carousel picking system. The optimal SKU arrangement of carousel systems in the literature mainly focuses on placing the SKUs in a way that minimises the total distance walked by pickers, or equally to minimise the total time to complete all orders [10]. The organ-pipe arrangement (OPA) and the greedy ranking and partitioning (GRP) are the most commonly used to solve the SKU location problem (SLP). Both the OPA and GRP methods classify and arrange SKUs according to their pick frequency. The pick frequency of a SKU refers to the number of orders that contain that SKU; simply put, the number of times a SKU is picked while completing orders. In the case considered here, the pick frequency refers to the number of times a SKU is picked to complete all of the orders during a specific wave of picking. When using the OPA to build a carousel, one would first place the most frequently-picked SKU on the carousel, the next most frequently-picked SKU adjacent to the first, the third most frequently-picked SKU to the other side of the first, and continue in this fashion [10]. The OPA method was introduced by Lim et al. [9], and in the case of bi-directional carousels with an expected set of stochastic orders, Litvak [10] has proved that the OPA is an optimal SKU arrangement under these conditions. This optimality refers to the minimisation of the distance travelled by the carousel. The OPA is probably a good method to use when a typical order on a carousel system is small, with respect to the total number of orders [1]. The OPA has the advantage of being easy to solve and set up. An example of a typical OPA SKU location solution is shown in Figure 3.

The GRP SKU arrangement method is very similar to the OPA. The GRP, which was introduced by Lim et al. [9], also classifies and arranges SKUs according to their pick frequency. The GRP method differs from the OPA in that it orders the SKUs in decreasing order of pick frequency. The GRP has also been shown to provide optimal SKU arrangements in certain conditions, with respect to the distance travelled by a carousel. An example of a typical GRP SKU location solution is shown in Figure 3. 

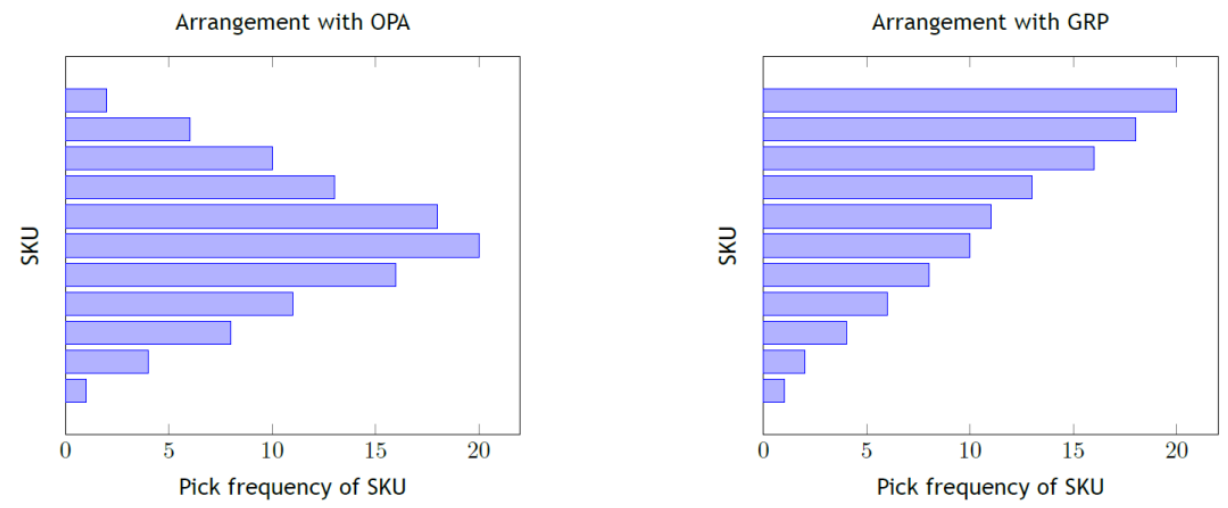

Figure 3: An example of typical OPA and GRP SKU location arrangements

The literature focuses on solving the SLP (for a carousel system) to minimise the distance rotated by the carousel. This is equivalent to the distance walked by the pickers in the picking line system considered here. The distance walked (or rotated) is, under the right conditions, optimal for normal bi-directional carousel systems, but unfortunately this optimality does not hold in the case of a unidirectional carousel (or picking line as considered here). The methods mentioned above led to minimal or no savings in distance travelled, relative to a random arrangement on the type of picking lines considered here. The focus is thus shifted to the congestion caused by the high-pick-frequency SKUs, and to the potential time that could be saved due to a reduction in congestion. In an attempt to spread out the SKUs with a high pick frequency as evenly as possible, a novel arrangement called the classroom discipline heuristic $(\mathrm{CDH})$ is introduced here.

\subsubsection{Classroom discipline heuristic}

The idea behind the CDH is to spread the SKUs out as evenly as possible (in terms of pick frequency) in a heuristic manner. The CDH mimics the dynamics of a classroom, where there are usually students with varying levels of discipline. If individual students with poor discipline are placed together in the classroom, the combined poor discipline will be increased as those students provoke each other; whereas if a student with poor discipline is adjacent to a student with good discipline, the combined discipline will be better. A teacher who has carte blanche over where the children are placed generally strives to create an even spread of less disciplined students among the better disciplined students. This principle may be adapted to the SKU arrangement on a picking line. The CDH regards the SKUs as students and the pick frequency of SKUs as the level of discipline.

The method is applied as follows: first, the SKU with the highest pick frequency is placed in the middle of the picking line. Second, the SKU with the second-highest pick frequency is placed in the middle of the left half of the picking line, and the SKU with the third-highest pick frequency is placed in the middle of the right half of the picking line. The following four SKUs (in terms of pick frequency) are then placed in the middle of the four openings between the already-placed SKUs, from right to left. The unplaced SKUs are repeatedly placed in the middle of the open spaces, from largest to smallest pick frequencies, moving alternately from the left to the right and then the right to the left. An example of the CDH applied to the set of SKUs with the following picking frequencies $\{15,13,12,9,7,6,3\}$ can be seen in Figure 4. 

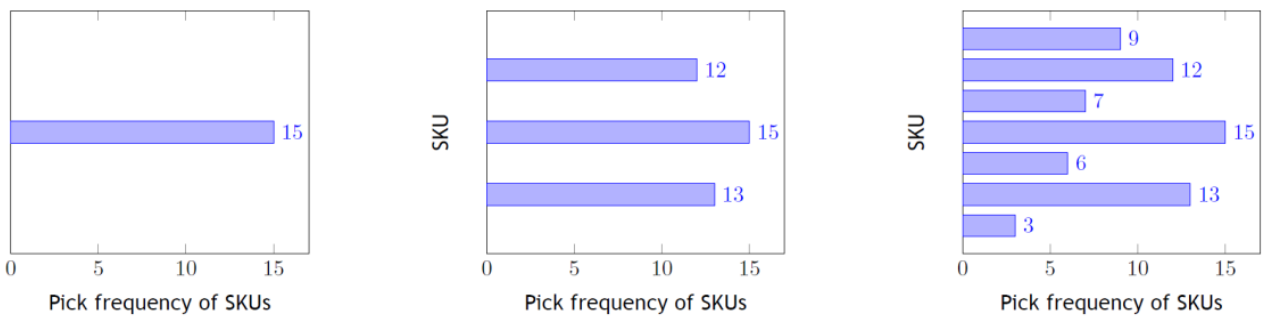

Figure 4: An example of the CDH SKU arrangement for the set $\{15,13,12,9,7,6,3\}$ of pick frequencies.

\subsubsection{SKU arrangement results}

The comparison between the OPA, GRP, historical, and CDH SKU arrangements is performed considering the total completion time and the fraction of time any picker stands still due to congestion. In general, the total completion times achieved using the $\mathrm{CDH}$ were shown to be less than the OPA, GRP, and historical SKU arrangements. The mean percentage time savings gained over all sixteen datasets by the CDH compared with the historical, OPA, and GRP SKU arrangements was 0.15 per cent, 1.81 per cent, and 0.5 per cent respectively (if eight pickers are used). This result is demonstrated in Figure 5 for the Large Dataset 1 . For this dataset, $\mathrm{CDH}$ performs better by 43 minutes than the GRP/historical when 13 pickers are used: this results in a saving of 5.27 per cent. If only seven pickers are used, a saving of 22 minutes is achieved, which translates to a 1.98 per cent saving. As expected, the percentage saved increases with an increase in pickers, as the total congestion increases with an increase in pickers. Similar savings were achieved with the other large datasets.

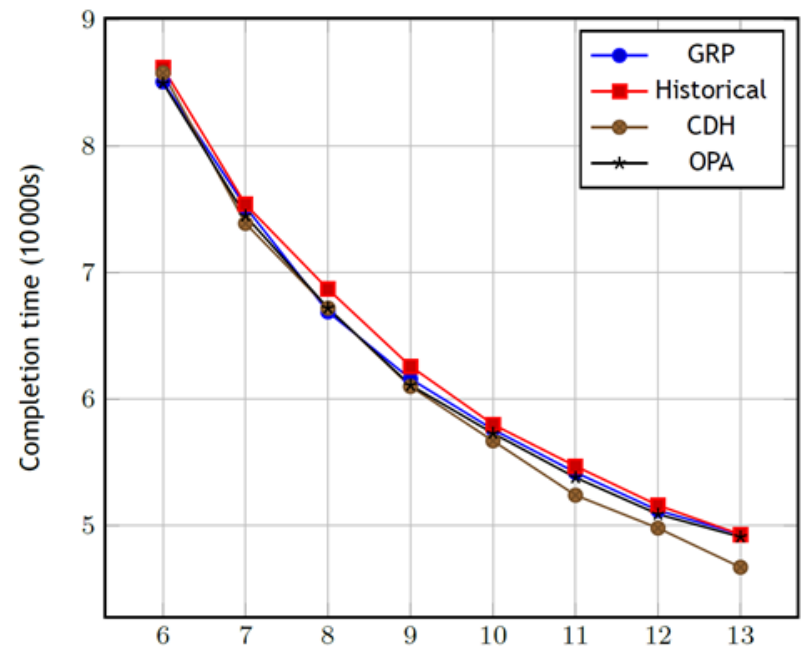

Figure 5: A comparison of the OPA, GRP, CDH, and historical SKU arrangements with respect to total completion time, according to the number of pickers for Large Dataset 1

It is interesting to see that the GRP actually performs better at eight pickers for the Large Dataset 1 , even though there is a more congestion. The reason for this is that the picking process involved a smaller number of cycles walked, meaning that the GRP SKU arrangement leads to fewer cycles walked in this case. The general savings when using the $\mathrm{CDH}$ were found to be less pronounced when working with smaller datasets: once again this is to be expected, as smaller lines have less congestion to resolve.

The fraction of time that pickers are congested, plotted over the number of pickers in the picking line for Large Dataset 1 , is graphed in Figure 6. This figure shows that there is a split between the fraction congestion differentiating the methods. The CDH SKU 
arrangement performs the best: it is about 5 per cent better than the GRP SKU arrangement when eight pickers are picking the line, and almost 12.5 per cent better than the GRP SKU arrangement when 16 pickers are used. The CDH SKU arrangement is also about 3 per cent better than the historical SKU arrangement at eight pickers, and almost 8 per cent better than the historical SKU arrangement at 16 pickers. On average (over all sixteen datasets for eight pickers), the total savings in congestion time using $\mathrm{CDH}$ relative to the historical, GRP, and OPA are 2.35 per cent, 6.73 per cent, and 10.73 per cent respectively.

During the simulation runs, the amount of congestion at each bay was also captured. When considering the congestion, it might be expected that there would be a strong correlation between the percentage picks and the percentage congestion at a specific location. Moreover, it was found that there is a strong correlation between the location with a high pick frequency and the location directly in front of it. This is due to pickers waiting for other pickers to finish their picking at the next location. It is thus desirable to have locations with lower pick frequencies in front of locations with higher pick frequencies. This is automatically achieved by means of the CDH. This effect is illustrated in the percentage congestion per location (for the first 10 locations), shown in Table 1.

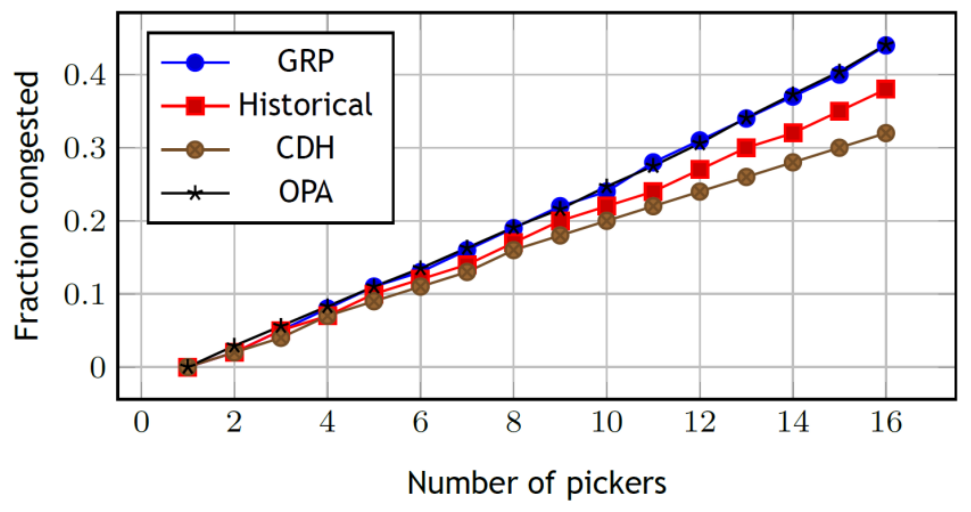

Figure 6: A comparison of the OPA, GRP, CDH, and historical SKU arrangements with respect to fraction congestion, according to the number of pickers for Large Dataset 1

Table 1: A comparison of the GRP, CDH, and historical SKU arrangements with respect to percentage picks and the corresponding percentage congestion for a selection of the first 10 bays, out of a total number of 56 bays, for Large Dataset 1. (The results for OPA are very similar to those of GRP, and are thus omitted from the table.)

\begin{tabular}{|c|c|c|c|c|c|c|}
\hline \multirow[b]{2}{*}{ Bays } & \multicolumn{2}{|c|}{ Historical } & \multicolumn{2}{|r|}{ GRP } & \multicolumn{2}{|r|}{$\mathrm{CDH}$} \\
\hline & $\%$ picks & $\%$ congestion & $\%$ picks & $\%$ congestion & $\%$ picks & $\%$ congestion \\
\hline 1 & 4.91 & 11.98 & 4.92 & 17.50 & 4.92 & 6.48 \\
\hline 2 & 3.06 & 7.12 & 4.91 & 8.00 & 1.17 & 1.81 \\
\hline 3 & 4.87 & 4.31 & 4.88 & 7.39 & 2.46 & 1.02 \\
\hline 4 & 2.98 & 6.56 & 4.88 & 6.93 & 1.03 & 1.51 \\
\hline 5 & 4.88 & 3.77 & 4.87 & 6.47 & 1.18 & 4.96 \\
\hline 6 & 2.92 & 6.38 & 4.85 & 5.77 & 4.87 & 0.84 \\
\hline 7 & 4.85 & 3.97 & 4.80 & 4.14 & 1.31 & 0.86 \\
\hline 8 & 2.99 & 6.42 & 4.20 & 2.45 & 1.00 & 2.17 \\
\hline 9 & 4.88 & 3.79 & 3.08 & 2.54 & 2.92 & 1.01 \\
\hline 10 & 3.00 & 5.87 & 3.06 & 2.80 & 0.94 & 1.91 \\
\hline
\end{tabular}

\subsection{The number of pickers in a picking line}

In the more commonly-used bi-directional carousal systems, only one picker is used per carousel, and thus the number of pickers is never investigated. No literature could be found 
dealing with the number of pickers to use when picking orders. Furthermore, the existing literature focuses on a situation where there are no picking lines; instead the pickers traverse aisles in the whole DC [4]. These aisles can be split into zones in which the pickers solely pick, increasing the efficiency in the DC. Gray et al. [8] maximise the picker use during any day where a specific number of orders is to be picked. The use of pickers is calculated by the expected number of orders for any day, the estimated time for a picker to complete a cycle through a zone, the length of a picking day, and the number of pickers assigned to a zone.

The approach that Gray et al. [8] suggest is not applicable in providing practical analysis for the picking line under consideration here. This is because the DCs in the literature do not have a deterministic number of orders to complete in any single day, and congestion is not taken into consideration (as zone picking largely circumvents congestion). Furthermore, the picker's picking and walking times are modelled too generally. The DC under consideration would want to complete any picking line as fast as possible to increase the DC flow, and thus to decrease the lead time to stores.

Two factors are considered while analysing the number of pickers in a picking line by means of the simulation model: minimising the total picking line completion time, while keeping the congestion at a controllable level.

Three techniques are considered to determine a 'good' number of pickers, with each approaching the problem in a different manner. The first, an absolute minimum approach, minimises only the completion time. The second technique, a critical limit approach, considers only the congestion. The third, a marginal analysis approach, considers the completion time and the picking line congestion simultaneously. The factors that affect a 'good' number of pickers for a specific picking line are the density of the picking line, the bay locations of the SKUs, and the SKU types.

In this study, the density of a picking line is defined in terms of the average number of bays between every pick, if one picker were to go through the picking line; thus pickers stop and pick more frequently as the density of picks increase. The frequency of picks affects the total amount of congestion and thus also affects what is considered to be the 'good' number of pickers. The SKU locations could be arranged so that SKUs that are picked the most frequently are adjacent to each other. This adjacency would lead to increased congestion around those SKUs and thus to a potential increase in total congestion affecting a 'good' number of pickers. The historical SKU locations were used to determine the 'good' number of pickers, as this allowed comparison with actual (and not simulated) results.

\subsubsection{Total completion time}

To see the overall effect of the number of pickers on the total completion time, an increasing number of pickers are inserted into the picking line, iteratively, over separate runs. It is expected that the total completion time will decrease as the number of pickers increases, and that at the same time the congestion will increase. It is further expected that at some point the amount of congestion, due to the number of pickers, will increase to the point where the total completion time starts increasing again. Tests using the simulation show that this expected pattern does occur, as can be seen in Figure 7.

It is interesting to note that the total completion time hits a relatively flat base at about ten pickers and stays there for quite a while, before starting to increase again at 40 to 45 pickers. This phenomenon is not completely counter-intuitive: as the number of pickers increases, there is naturally more congestion, yet there are also more pickers to complete orders. What is unexpected is that the number of pickers has to increase significantly (to around 40 ) before there is a noticeable increase in total completion. 


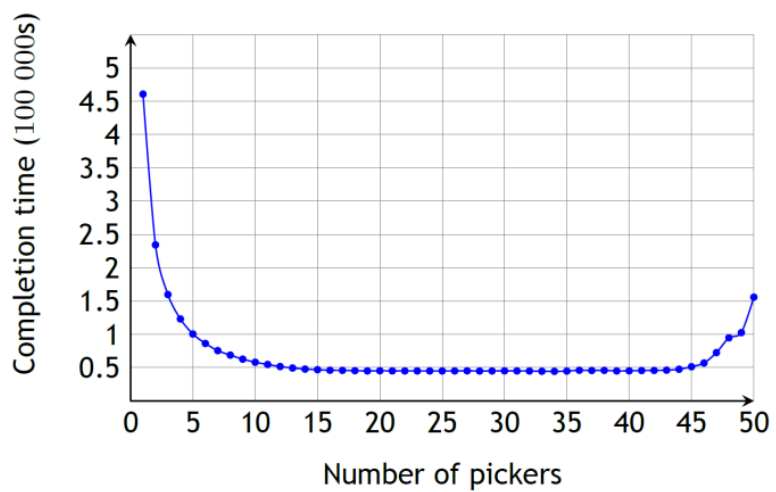

Figure 7: A plot of the total completion time in, over the number of pickers, for Large Dataset 2.

\subsubsection{Critical limit on congestion}

The average fraction of time that a picker is in the congested state during the completion of the picking line is also measured during the simulation runs. In this approach, a user can decide on an acceptable percentage of congestion (the critical limit). The simulation data reveals that the percentage increases roughly linearly, to the point that when there are 45 pickers, there is almost 75 per cent percent congestion. An example of the percentage congestion as a function of the number of pickers is provided in Figure 8. From such a graph, a user can determine the 'good' number of pickers that will keep the percentage congestion below a predetermined critical level. For the example in Figure 8, the critical level of congestion was set at 15 per cent. This level is reached at around 8 pickers working in the line.

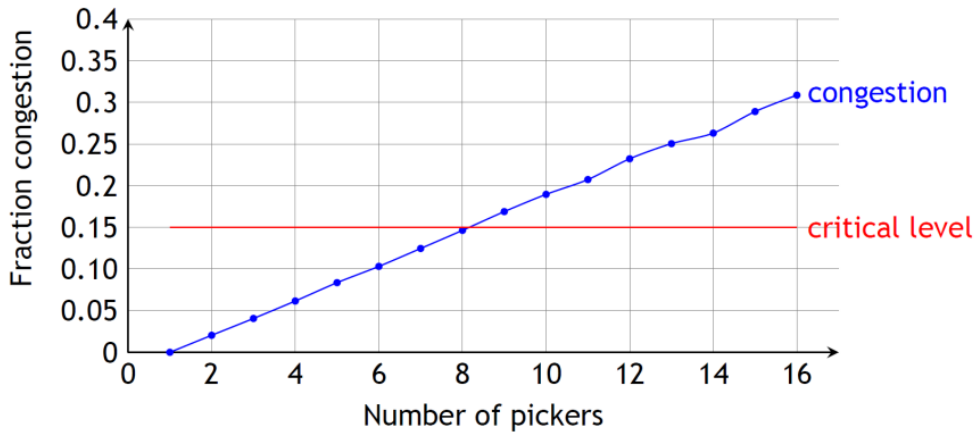

Figure 8: The critical level on Large Dataset 2

\subsubsection{Marginal analysis}

The marginal analysis (MA) method is proposed as the most realistic method, as it considers both congestion and total completion time. The absolute minimum technique, choosing the number of pickers that minimised the completion time, provided a solution with an unacceptable amount of congestion. The critical limit technique of choosing the number of pickers, once the congestion went over a certain critical limit, provided realistic results. However, it is difficult to determine an acceptable amount of congestion.

MA is a process in which the additional benefits and costs caused by the inclusion of an extra unit are weighed up against each other. Using MA, one would typically add an extra unit to the system repeatedly, until the point where the additional benefit is less than the cost. At this point the number of units is the best for the system. 
In determining the number of pickers with MA, the additional benefit is defined as the marginal total completion time decrease that comes with the addition of one picker. Simply put, if one inserts an extra picker into the picking line, by how much does the total completion time decrease? The additional cost is seen as the increase in total congestion time that occurs with the addition of one extra picker into the picking line.

An example of the MA performed on a historical data instance is shown in Figure 9. For this example, it can be seen that the additional picking time gained by an extra picker becomes less than the additional congestion time added by an extra picker between six and seven pickers; thus it can be said that a 'good' number of pickers for this line is about six or seven. The results, over all datasets, are summarised in Table 2. These results show that there is, as expected, a correlation between the density of a picking line and a 'good' number of pickers. The correlation coefficient in this case is 0.84 over all the historical datasets, which is significant.

In addition, the number of pickers determined by MA is very close to the number of pickers (around 7 to 10) that the picking line managers at PEP found, from experience, to be a 'good' number of pickers for a picking line. These results enable picking line managers to predetermine what will be a 'good' number. Currently the number of pickers is determined by adding and removing pickers until picking speed and congestion seem to be in balance.

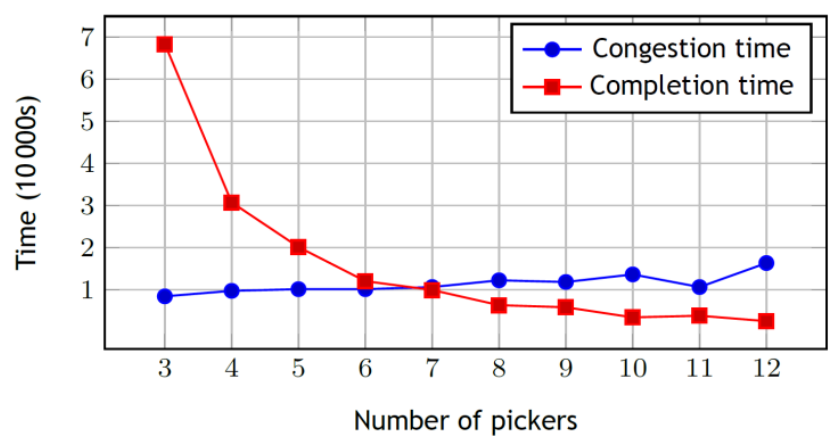

Figure 9: Marginal analysis performed on Large Dataset 3, comparing the fraction decrease of average congestion for any picker against the fraction increase in total time

Table 2: A summary of the results over all historical datasets to determine a 'good' number of pickers for picking lines

\begin{tabular}{ccc}
\hline Dataset & Density & Good number of pickers \\
\hline \multirow{2}{*}{ Large } & $(2,3.5)$ & 7 \\
& {$[3.5, \infty)$} & 8 \\
\hline \multirow{2}{*}{ Medium } & $(12,16)$ & 9 \\
& {$[16,23)$} & 10 \\
\hline Small & $\mathrm{n} / \mathrm{a}$ & 11 \\
\hline
\end{tabular}

\section{CONCLUSION}

The main objective of this paper was to simulate the picking process at PEP's Durban DC by means of ABMS, and then to provide analysis on two separate problems using this simulation. It was built to include the observed individual and inter-picker behaviour of actual order pickers at PEP, and to model the environment within which they pick. Data was collected from historical datasets and video footage to determine picker-specific characteristics such as walking velocity and picking and packing times, and was included in the simulation. The simulation was verified and validated visually and against historical data; the verification and validation revealed that the simulation does indeed model the real-life picking line with a satisfactory degree of accuracy. 
The problem related to the initial SKU arrangement while building a picking line compared methods from the literature, the historical SKU arrangement, and a novel method called the $\mathrm{CDH}$. The $\mathrm{CDH}$ proved to provide an efficient SKU arrangement for the situation at the DC because it causes, on average, the lowest levels of congestion.

The problem related to the calculation of a 'good' number of pickers in a picking line considered three different techniques. It was shown that MA provided the most realistic results. It provides a tool for PEP to predetermine a 'good' number of pickers for a picking line, based on the picking line properties before picking commences. The results in this paper were presented to PEP, and their implementation is in the planning phase.

For future research, it might be beneficial to use this model to simulate different layouts. For example, it is clear from the results that smaller picking lines, with regard to the number of orders, can be picked with a greater number of pickers, as less congestion is created. It would be an interesting study to consider the financial viability of increasing the size of the warehouse, and creating more (and thus smaller) picking lines so that the average size of the picking lines is smaller. It would also be interesting to consider the physical size of the picking lines in relation to the number of bays, and determine what the best number of bays in a picking line should be.

\section{REFERENCES}

[1] Bartholdi, J.J. \& Platzman, L.K. 1986. Retrieval strategies for a carousel conveyor. IEEE Transactions, 18(2), pp. 166-173.

[2] Bonabeau, E. 2002. Agent-based modelling: Methods and techniques for simulating human systems. Proceedings of the National Association of Sciences, 99(3), pp. 7280-7287.

[3] Burghout, W. 2004. A note on the number of replications runs in stochastic traffic simulation models. Unpublished report, Stockholm: Centre for Traffic Research.

[4] De Koster, R., Le-Duc, T. \& Roodbergen K.J. 2007. Design and control of warehouse order picking: A literature review. European J ournal of Operational Research, 182(2), pp. 481-501.

[5] De Villiers, A.P., Matthews, J. \& Visagie, S.E. 2012. Tour construction heuristics for an order sequencing problem. South African J ournal of Industrial Engineering, 23(2), pp. 5667.

[6] De Villiers, A.P., Matthews, J. \& Visagie, S.E. 2013. Metaheuristic approaches to order sequencing on a unidirectional picking line. ORiON, 29(1), pp. 55-73.

[7] Gong, Y. 2009. Stochastic modelling and analysis of warehouse operations. Doctoral Thesis, Erasmus University of Rotterdam.

[8] Gray, A.E., Karmarkar, U.S. \& Seidmann, A. 1992. Design and operation of an orderconsolidation warehouse: Models and application. European Journal of Operational Research, 58(1), pp. 14-36.

[9] Lim, W.K., Bartholdi, J.J . \& Platzman, L.K. 1985. Storage schemes for carousel conveyors under real time control, Technical Report, Material Handling Research Center Tech, Atlanta: Georgia Institute of Technology.

[10] Litvak, N. 2006. Optimal picking of large orders in carousel systems. Operations Research Letters, 34(2), pp. 219-227.

[11] Macal, C.M. \& North, M.J . 2010. Tutorial on agent-based modelling and simulation. Journal of Simulation, 4(3), pp. 151-162.

[12] Matthews, J. \& Visagie, S.E. 2013. Order sequencing on a unidirectional cyclical picking line. European J ournal of Operational Research, 231(1), pp. 79-87.

[13] PEP. 2013. Pep. Retrieved from http:// www. pepstores. com. Accessed in J une, 2013.

[14] Robinson, S. 1997. Simulation model verification and validation: Increasing the users' confidence. Proceedings of the 29th Winter Simulation Conference, pp. 53-59.

[15] Sargent, R.G. 1991. Simulation model verification and validation. Proceedings of the 23rd Winter Simulation Conference, pp. 37-47.

[16] Sun Microsystems. 2012. Java. Retrieved from http://java. sun. com/. Accessed on $24^{\text {th }}$ October, 2014.

[17] XJ Technologies. 2012. Anylogic 6.5.1. Retrieved from http:// www.xjtek.com/. Accessed on $24^{\text {th }}$ October, 2012. 